\title{
USE OF LOCALLY AVAILABLE FLAVOURING MATERIALS IN SUPPRESSING THE BEANY TASTE IN SOYMILK
}

\author{
Laswai HS*1, Thonya $\mathbf{N}^{1}$, Yesaya $\mathrm{D}^{1}$, \\ Silayo VCK ${ }^{2}$, Kulwa $\mathrm{K}^{1}$, Mpagalile $\mathrm{JJ}^{1}$ and WRW Ballegu ${ }^{1}$
}

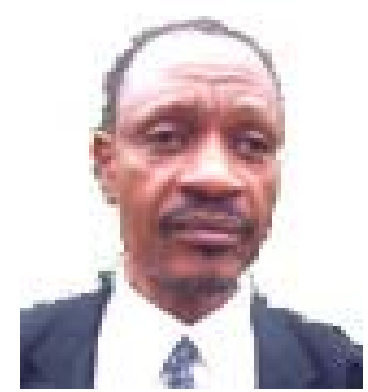

Laswai Henry

*Corresponding author email: hs2laswai@yahoo.com

${ }^{1}$ Department of Food Science and Technology, SUA, P.O. Box 3006, Chuo Kikuu, Morogoro, Tanzania.

${ }^{2}$ Department of Agricultural Engineering and Land Planning, SUA, P.O. Box 3003, Chuo Kikuu, Morogoro, Tanzania. 


\section{ABSTRACT}

Soymilk is a good replacement of cow's milk in places where cow's milk is not available in sufficient quantity. Acceptability of this soymilk as cow's milk substitute is greatly influenced by flavour. Blending with common fruits like bananas and pineapples and other low cost ingredients as flavouring agents such as lemon grass, honey or sugar to suppress the unpleasant flavour in soybean-based products has not been fully investigated in Tanzania. The objective of this study was to assess the effect of blending soymilk with pineapple, banana, lemongrass, honey or sugar on acceptability of the resulting blends. Sensory evaluation involving 25 semi-trained panelists in two different studies employed a five point hedonic scale (1=Dislike extremely, 5=Like extremely and 3=Neither like nor dislike) to assess the extent of liking of the blends. The attributes investigated were colour, taste, smell, appearance and general acceptability. Pineapple-flavoured blends were more acceptable than the banana flavoured ones. Banana-flavoured blends resulted in phase separation that accounted for the relatively low acceptance. Soymilk from different soybean varieties also showed variation in acceptability. Regarding overall acceptability, with the exception of the banana-flavoured milk samples that were unacceptable or marginally acceptable, soymilk samples from Kaleya, Duicker and Sable varieties were more acceptable than the rest. With reference to lemon grass, honey and sugar, mean scores of appearance of soymilk ranged between 3.5 and 3.8 with cow's milk the highest (mean score 4.7). Colour ranged from 3.0 to 4.0 for the products (cow's milk 4.9). The mean score range for odour was 2.8 to 4.2 (cow's milk 4.2), taste 3.2 to 4.6 (cow's milk 4.3) and overall acceptability 3.0 to 3.8 (cow's milk 4.6). Cow's milk was significantly $(\mathrm{p}<0.05)$ superior in all parameters studied with the exception of taste, where lemon grass-flavoured the soymilk more (mean 4.6) than cow's milk (mean 4.3) although there was no significant difference ( $p>0.05)$ between the two products. Common fruits like banana and pineapple as well as lemon grass and honey could be used in promoting acceptability of soymilk where cow's milk is either unaffordable or unavailable or there is lactose intolerance in the community. Increased use of these beany flavour suppressants and more investigations to expose other promising flavouring agents are recommended.

Key words: soymilk, acceptability, lemon grass, fruits 


\section{INTRODUCTION}

Milk is an important source of proteins, vitamins and minerals. Although the general public is usually aware of the importance of milk and milk products, per capita milk intake in Tanzania of 40 litres/annum[1] is low. This is mainly due to low milk production, prevalent animal diseases, unaffordability by majority of low income households together with unavailability [2]. Many parts of Tanzania cannot support livestock keeping. This makes it difficult for many households to rely on milk from animals for feeding children. In this regard, they rely on other foods for such children and this practice cannot cater for the infants who cannot eat solid food. Therefore cow's milk substitute like soymilk becomes necessary but difficult to obtain.

Soymilk shows bright future due to recent promotion of its production, processing, utilization and marketing in Tanzania [1]. Bulk sales of soybean to the food industry (as for use in baked foods or in fast food establishments in place of milk) also hold great promise, with many opportunities for innovation as a dairy extender or analogue. Using soymilk in Third World countries will decrease losses of precious foreign exchange used on milk imports. Furthermore, it will allow the implementation or expansion of feeding programmes for nutritionally at-risk infants and school children, decrease costs and increase protein availability for the general population. It will also aid in the potential establishment of new soymilk plants and related jobs prevent problems of lactose intolerance and help combat chronic milk shortage [3].

Soymilk is growing in popularity and it is being marketed as an alternative to cow's milk [4]. It is cheap and majority of low-income households in rural Tanzania could afford it. Although soymilk has different nutritional properties, it is marketed as though it was a milk product possessing similar nutritional properties as cow's milk [2]. Despite these marketing efforts, little has been done to assess consumer perception of soymilk as cow's milk substitute.

Despite the wide variety of uses soymilk is still not consumed to the extent expected, due to the undesirable beany flavour [5]. Acetaldehydes, acetone and n-hexanal are the major carbonyl compounds found in soybean. N-hexanal has a low flavour threshold and is believed to contribute to the beany flavour. It is believed to be a product of oxidation of polyunsaturated fatty acids by oxygenase [6]. Many of the flavours found in soybean products, particularly soymilk may be generated enzymatically by lipoxygenase, resulting during the initial grinding step [7].

Approaches towards beany flavour removal include heat inactivation of the enzyme in whole dry bean during grinding process, starting with defatted material. Alternatively, this can be done by removal of the flavour compounds by evaporation after they have been formed in soymilk or by masking the bitterness and off flavours with sweetening and flavourings like chocolate or coffee. Off- flavours can also be avoided through genetic engineering of varieties of soybeans devoid of lipoxygenase activity [8]. Soaking the beans in a $1 \%$ sodium bicarbonate gives a slight improvement in flavour and treatment with sodium hydroxide markedly improves off-flavour of soymilk as a

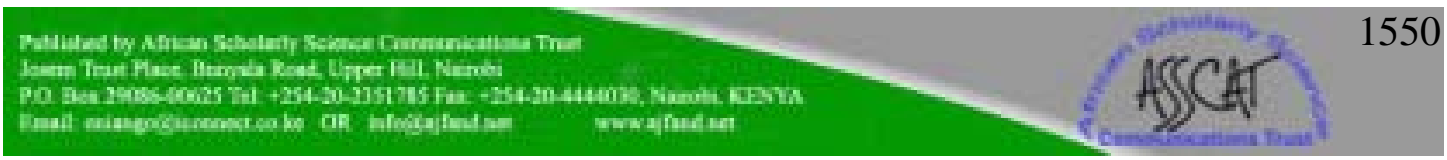


consequence of inactivating the lipoxidase $[8,9]$. Lemon grass is an aromatic herb rich in citral, the aldehyde responsible for the lemon odour and is safe for human consumption as plant extract or essential oil. It is used as scent for many food products and soap, perfumes and candles. It is used to release flavour in a variety of food products like tea [10]. Honey has a distinctive flavour which leads to some people to prefer it to sugar and other sweeteners in various beverages such as tea [11]. Another benefit of sugaring is that the beany flavour is greatly suppressed. Lipoxygenase is a primary culprit and linolenic acid is a primary precursor when soybeans are partially processed before destroying the enzymatic activity [12]. Another drawback in soybean use is the astringency that is generally due to the polyphenolic substances present in soymilk that interact with mucoprotein in the mouth and throat [13].

The fact that soymilk does not taste the same as cow's milk poses many challenges regarding acceptability. This study was, therefore, conducted to assess suitability of different soybean varieties cultivated in Tanzania for soymilk production and further investigate the effect of blending with pineapple, banana, lemon grass, and honey or sugar on acceptability of the resulting blends.

\section{MATERIALS AND METHODS}

Source of raw materials: This study is a two part experiment. The first part involved using banana pulp and pineapple extract to impart flavour to the soymilk. The second part used lemon grass, honey or sugar to mask the beany flavour in the soymilk. Banana and pineapple were obtained from Morogoro municipal market while lemon grass was freshly harvested from Sokoine University of Agriculture Horticulture unit. Honey and sugar were purchased from Morogoro Municipal groceries.

Preparation of banana pulp and pineapple extract: Ripe bananas (Musa sp. variety Mtwike) that had ripened to the extent of formation of dark spots on the peel were peeled and homogenized in a Waring blender. They were then added to the soymilk in the proportion indicated in methodology. The pineapple was washed with potable water and cut into small pieces to facilitate juice extraction. They were then carefully squeezed in a muslin cloth to get the extract that was used in the blending as explained in the methodology.

Preparation of soymilk: Dried soybean varieties obtained from the Soybean Project (Sokoine University of Agriculture, Morogoro) were used. These included TGX 1876$2 E$, Black soybean (ex-Songea), Kaleya, Duicker, Sable and TGX 1805-8E varieties. Soymilk was prepared as shown in the flow diagram (Fig. 1). The lemon grass was washed and then chopped into about $1 \mathrm{~cm}$ long pieces

Blending of soymilk with banana and pineapple fruit extracts: Banana fruit extract was prepared by homogenization in a Waring blender and pineapple fruit extract was obtained by squeezing the ripe sliced fruit to obtain the juice that finally formed $14 \%$ $(\mathrm{v} / \mathrm{v})$ and $13 \%(\mathrm{v} / \mathrm{v})$ for banana extract and pineapple juice, respectively.

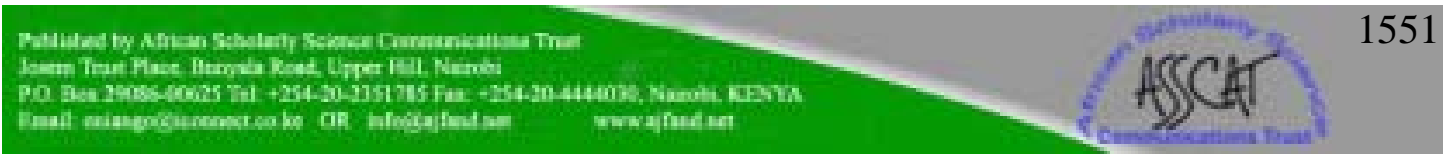


Blending of soymilk with lemon grass, honey or sugar: In the second study, soymilk was blended to obtain the formulations shown in Table 1.

Whole soybean

$\downarrow$

Sort and clean with potable water

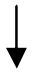

Boil in water for 30 minutes

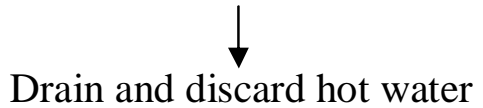

$\downarrow$

Pour cold water on the boiled soybean

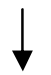

Remove hulls using clean hands

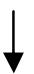

Wash to remove hulls

$\downarrow$

Dry soybean using solar drier to $15-16$ content wet basis

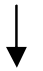

Grind into flour

$\downarrow$

Take $250 \mathrm{~g}$ flour and boil in $2500 \mathrm{ml}$ water for 30 minutes with frequent stirring<smiles>C1CCCCC1</smiles>

Filter using cheese cloth

$\downarrow$

Plain soymilk

Figure 1: Processing of soymilk 
Sensory evaluation: Sensory evaluation was conducted using 25 semi-trained panelists, using a 5 point hedonic scale, where 5= Like extremely, 4=Like moderately, $3=$ Neither like nor dislike, 2=Dislike moderately and 1=Dislike extremely. Parameters investigated included colour, appearance, taste, odour, and general acceptability.

Statistical analysis: After coding, data analysis was done using M-Stat C programme to get the mean scores. These means were compared and separated for significance using Duncan's Multiple Range Test.

\section{RESULTS}

Soymilk from different soybean varieties showed variation in acceptability. Using a 5point hedonic scale, irrespective of variety of soybean, soymilk had the following ranges of acceptability for the different parameters studied. Appearance of plain soymilk 3.00-3.92, pineapple-flavoured soymilk 3.00-3.42 and banana-flavoured soymilk was 2.46-2.88 and cow's milk 4.75. The colour ranges were: plain soymilk 3.13-3.83, pineapple-flavoured soymilk 3.20-4.00 and banana-flavoured soymilk 2.21-2.88 and cow's milk 4.92. The taste of the soymilk was: plain soymilk 3.13-3.58, pineapple-flavoured soymilk 3.13-3.88 and banana-flavoured soymilk 3.00-3.54 and cow's milk 3.71. The aroma of the soymilk was plain soymilk 3.04-3.42, pineappleflavoured soymilk 3.25-4.21 and banana-flavoured soymilk 2.96-3.54 and cow's milk 4.17. The overall acceptability range was: plain soymilk 3.21-3.75, pineappleflavoured soymilk 3.29-3.92 and banana-flavoured soymilk 2.75-3.42 and cow's milk 4.38. Cow's milk was significantly $(\mathrm{p}<0.05)$ superior in all parameters studied with the exception of taste,

Sensory evaluation mean scores of lemon grass-, honey- and sugar-flavoured soymilk formulations are shown in Table 3. The appearance of the differently flavoured soymilks ranged from 3.5-3.8 with no significant variation $(\mathrm{p}>0.05)$ but these mean scores were significantly $(\mathrm{p}<0.05)$ inferior to cow's milk (mean $=4.7)$. The colour mean scores also differed significantly $(\mathrm{p}<0.05)$ from that of cow's milk (mean=4.9). The soymilk flavoured with sugar was significantly more accepted than others in terms of colour. The aroma of the sugar-flavoured soymilk was not accepted and the remaining with the exception of the lemon grass flavoured and cow's milk that was equally accepted was marginally accepted but not significantly different from the sugar-flavoured soymilk. Flavouring with lemon grass resulted in soymilk that was more acceptable but not significant from cow's milk. These two milk samples were significantly more accepted than the remaining flavoured soymilk types. The remaining mean scores did not differ significantly but were significantly lower than the mean score of the lemon grass-flavoured soymilk.

Overall, the lemon grass-flavoured soymilk was more accepted (mean=4.6) than cow's milk (mean $=4.3)$ although there was no significant difference $(p>0.05)$ between the two products. 


\section{DISCUSSION}

Results showed that generally, pineapple-flavoured soybean blends were more acceptable than the banana-flavoured ones (Table 2). Banana-flavoured blends resulted in phase separation that accounted for the relatively low overall acceptance. The pulp added to the milk made it more viscous thus encouraged the components to separate after settling. Earlier studies have also shown that banana and pineapple flavours are effective in suppressing the beany flavour, thus resulting in more acceptable products [14]. When the pulp is used, it produces a similar flavour but changes the viscosity. Such pulp can thus find use in more viscous dairy-like soybean products, like yoghurt or milk shakes as has also been demonstrated [3,14].

When used in the mentioned products, soybean serves many functions like nutritional and functional $[3,14]$ Four important considerations need to be made when adding soybean ingredients to products. These include taste, colour, functionality and cost. Of these four considerations, taste is the most important [15]. The sensory attributes that seem closely related to this taste are odour, texture and mouth feel. These eventually assist in deciding overall acceptability of these soybean-based products. This implies that to get acceptable soybean-based products like blended soymilk, the beany flavour problem should be suppressed or removed to avoid affecting negatively the overall acceptability of the resulting blend.

Increasing popularity in consumption of soybean has three prerequisites that are: it must sell for less than cow's milk, have good taste and must be marketed effectively [15]. The greatest potential of soymilk lies in the Third World countries, where sources of tasty, low cost protein and energy are in greatest demand. It is also true that it is in such places where obstacles to increasing milk supplies exist due to low milk yield by indigenous cattle and existence of high incidences of animal diseases [16]. It is an added advantage to promote soymilk consumption due to current promotion of this soybean in many places including Tanzania that has resulted in increased cultivation.

Soymilk from the different soybean varieties also showed variation in acceptability (Table 2). It is important to therefore note that, based on the two types of fruits used in this study, not every fruit type can be blended with soymilk to produce acceptable blend, however nice it may be organoleptically. While success may come from improving the flavour there are also serious drawbacks like this one of changing the consistency of soymilk and consequently bringing about phase separation. Also, acidic fruits will encourage coagulation and thus destabilize the system. Soymilk is difficult to blend with acidic fruits like the citrus fruits since the isoelectric $\mathrm{pH}$ of the proteins in the soymilk can be reached. When such a situation is encountered then isoelectric precipitation of such proteins will occur leading to phase separation of the blend. Using less acidic fruits like pawpaws can salvage this situation because pawpaws are generally associated with low acidity. This warrants more research to confirm this possibility and evaluate the acceptability of flavour of the resulting milk.

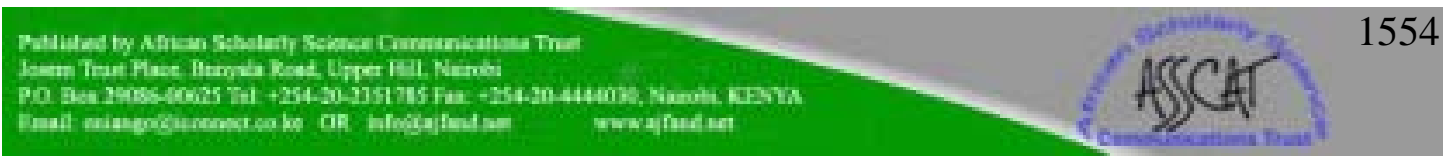


Besides flavouring the milk, fruits like bananas and pineapples are potential sources of other important nutrients like vitamins. Vitamin $C$ is among those vitamins that could improve nutrient status of the fruit flavoured soymilk. This implies that the blending will do more than just suppressing the beany flavour and when fed to children it will have a nutritional benefit.

The results in Table 3 show that soybean milk was accepted to varying degrees depending on the type of flavouring agent used. In this study common sugar, honey and lemon grass were investigated regarding their impact on increasing acceptability of the soymilk. Sugar used as a sweetener resulted in a product that was acceptable in all the sensory attributes investigated in this study with the exception of odour that was not pleasant. This could be due to the fact that these flavouring agents were unable to mask the beany flavour. Use of honey or lemon grass eliminated the unpleasant odour and increased acceptability of this milk. The results further showed that lemon grass was excellent in masking the beany flavour, improving the taste and general acceptability of the soymilk. Honey was also more effective than cane sugar in masking this flavour as evidenced by relative improvement in the odour, although the improvement was not significant $(p>0.05)$. Use of these flavouring agents could enhance consumption of soybean in form of soymilk and could in the long run impact on reducing Protein Energy Malnutrition (PEM) in the community as also reported elsewhere [16].

Cow's milk, a familiar food commodity to all panellists, was consistently superior in all the attributes investigated but it was interesting to note that the taste of soymilk that contained lemon grass flavour and sugar was more accepted than the plain cow's milk although the difference was not significant ( $p>0.05$ ). These results showed that instead of using fruits or fruit flavours to flavour soybeans and reduce beany flavour there are still other promising alternatives. A good alternative demonstrated by this study and one that can be immediately exploited is lemon grass that is also used to flavour tea. Lemon grass is commonly used in teas, soups, and curries. It is also suitable for poultry, fish, and seafood [17]. Use of lemon grass is cost-effective since it is cheap to raise enough quantity and in addition, it can be dried for use during times of scarcity. It appears, therefore, adaptable to most households in the rural areas and in other resource-poor households for example in peri-urban areas. This can ensure sustainability in the production and consumption of soybeans in Tanzania. Those consumers who were once threatened by the beany flavour and thus abandoned consumption of soybean as it is or in the form of soymilk could change minds and contribute to increasing the number of soybean consumers.

Honey plays a role as a sweetener as well as a flavour improver. Cane sugar on the other hand assists in improving the sweetness and thus will have much influence on the taste of the product. As indicated in literature, the major problem in expanding the use of soymilk is the beany flavour [18]. Therefore, use of honey in soymilk could be exploited as one of the attempts in increasing soybean consumption. More studies have further shown that modern processing techniques produce bland soymilk without beany flavour and more like cow's milk in taste. Soymilk made with soy flour with

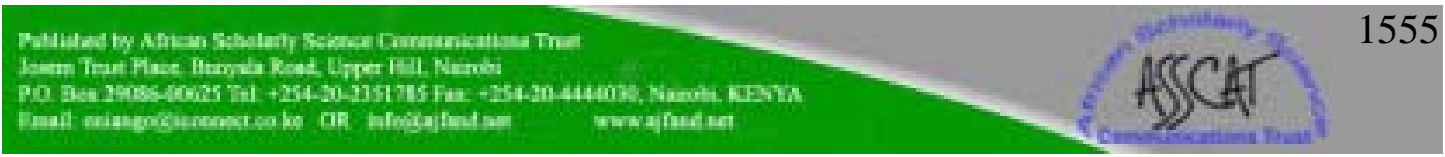


$2 \%$ sucrose and $2.5 \%$ refined soy flour was rated as acceptable as cow's milk. Soymilk can be passed through a vacuum pan at high temperature to remove most of the volatile off-flavour compounds. Fermentation also reduces the flavour. Beany flavour of soymilk can be masked and the flavour improved by addition of flavourings and sweeteners like vanilla, milk, egg, chocolate and honey. Alkaline soaking or acidic grinding of soybean at $\mathrm{pH}$ below 3 also removes the beany flavour and produces milk that has no beany flavour but is not used commercially [18]. These studies expose the whole range of possible food processing options that can be taken to minimize beany flavour in soymilk.

\section{CONCLUSION}

Fruits could be used in masking the beany flavour thus promoting acceptability of soymilk. This could be beneficial to communities where cow's milk is unacceptable, unavailable or unaffordable or due to lactose intolerance. Lemon grass was the best among the tested flavouring materials in masking the beany flavour, improving the taste and general acceptability. Honey was next to lemon grass and was more effective than sugar in masking this flavour.

\section{RECOMMENDATION}

Use of these beany flavour masking agents could enhance consumption of soybean in form of soymilk and thus need to be promoted as one of the cost-effective sustainable approaches in the promotion of wide soybean consumption in Tanzania.

\section{ACKNOWLEDGEMENT}

The authors are very grateful to the SUA Programme for Agricultural Transformation for Improved Livelihoods (PANTIL) for financial support availed for this study. 
Table 1: Formulation of soymilk blends

\begin{tabular}{ll}
\hline Formulation & Blending proportions \\
\hline Plain soymilk + sugar & $2 \mathrm{~L}$ milk + Boiled $+60 \mathrm{~g} / \mathrm{L}$ sugar \\
Soymilk +lemon grass + honey & 2 All milk + boiled with $100 \mathrm{~g}$ lemon grass + \\
& filtered $+120 \mathrm{~g}$ honey \\
Soymilk + lemon grass + sugar & $100 \mathrm{~g}$ lemon grass $+60 \mathrm{~g} / \mathrm{L}$ sugar \\
Soymilk+honey & $2 \mathrm{~L} \mathrm{milk}+120 \mathrm{~g} / \mathrm{L}$ honey \\
\hline
\end{tabular}

Table 2: Acceptability of fruit flavoured soymilk from different soybean varieties

\begin{tabular}{|c|c|c|c|c|c|}
\hline Sample & Appearance & Colour & Taste & Aroma & $\begin{array}{l}\text { General } \\
\text { acceptability }\end{array}$ \\
\hline \multicolumn{6}{|l|}{ TGX 1876-2E } \\
\hline Plain & $3.42^{\mathrm{d}}$ & $3.33^{\mathrm{d}}$ & $3.21^{\mathrm{b}}$ & $3.04^{\mathrm{d}}$ & $3.29^{\mathrm{d}}$ \\
\hline +pineapple & $3.42^{\mathrm{d}}$ & $3.92^{\mathrm{a}}$ & $3.29^{\mathrm{a}}$ & $3.33^{\mathrm{b}}$ & $3.38^{\mathrm{c}}$ \\
\hline + banana & $2.54^{\mathrm{j}}$ & $2.38^{\mathrm{j}}$ & $3.00^{\mathrm{d}}$ & $2.96^{\mathrm{d}}$ & $2.83^{\mathrm{g}}$ \\
\hline \multicolumn{6}{|l|}{ Black soybean } \\
\hline Plain & $3.13^{\mathrm{f}}$ & $3.20^{\mathrm{e}}$ & $3.42^{\mathrm{a}}$ & $3.20^{c}$ & $3.29^{\mathrm{d}}$ \\
\hline +pineapple & $3.33^{\mathrm{e}}$ & $3.33^{\mathrm{d}}$ & $3.25^{\mathrm{a}}$ & $3.29^{\mathrm{b}}$ & $3.29^{\mathrm{d}}$ \\
\hline + banana & $2.46^{\mathrm{k}}$ & $2.21^{\mathrm{j}}$ & $3.25^{\mathrm{a}}$ & $3.04^{\mathrm{d}}$ & $2.75^{\mathrm{h}}$ \\
\hline \multicolumn{6}{|l|}{ Kaleya } \\
\hline Plain & $3.54^{\mathrm{b}}$ & $3.75^{b}$ & $3.58^{\mathrm{a}}$ & $3.33^{\mathrm{b}}$ & $3.63^{\mathrm{b}}$ \\
\hline +pineapple & $3.75^{\mathrm{b}}$ & $3.96^{\mathrm{a}}$ & $3.88^{\mathrm{a}}$ & $3.83^{\mathrm{a}}$ & $3.92^{\mathrm{b}}$ \\
\hline + banana & $2.75^{\mathrm{i}}$ & $2.88^{\mathrm{g}}$ & $3.50^{\mathrm{a}}$ & $3.25^{\mathrm{b}}$ & $3.21^{\mathrm{e}}$ \\
\hline \multicolumn{6}{|l|}{ Duicker } \\
\hline Plain & $3.83^{b}$ & $3.63^{\mathrm{b}}$ & $3.46^{\mathrm{a}}$ & $3.42^{\mathrm{b}}$ & $3.67^{b}$ \\
\hline +pineapple & $3.46^{\mathrm{c}}$ & $3.42^{\mathrm{c}}$ & $3.83^{\mathrm{a}}$ & $4.21^{\mathrm{a}}$ & $3.88^{\mathrm{b}}$ \\
\hline + banana & $2.88^{h}$ & $2.67^{\mathrm{i}}$ & $3.54^{\mathrm{a}}$ & $3.54^{\mathrm{b}}$ & $3.42^{\mathrm{b}}$ \\
\hline \multicolumn{6}{|l|}{ Sable } \\
\hline Plain & $3.92^{\mathrm{b}}$ & $3.83^{\mathrm{b}}$ & $3.50^{\mathrm{a}}$ & $3.38^{\mathrm{b}}$ & $3.75^{b}$ \\
\hline +pineapple & $4.00^{b}$ & $4.00^{\mathrm{b}}$ & $3.42^{\mathrm{a}}$ & $3.54^{\mathrm{b}}$ & $3.75^{b}$ \\
\hline + banana & $2.88^{\mathrm{h}}$ & $2.71^{\mathrm{i}}$ & $3.54^{\mathrm{a}}$ & $3.46^{\mathrm{b}}$ & $3.25^{\mathrm{d}}$ \\
\hline \multicolumn{6}{|l|}{ TGX 1805-8E } \\
\hline Plain & $3.00^{\mathrm{g}}$ & $3.13^{\mathrm{f}}$ & $3.13^{c}$ & $3.25^{\mathrm{b}}$ & $3.21^{\mathrm{e}}$ \\
\hline +pineapple & $3.00^{\mathrm{g}}$ & $3.21^{\mathrm{e}}$ & $3.13^{c}$ & $3.75^{\mathrm{a}}$ & $3.29^{\mathrm{d}}$ \\
\hline + banana & $2.58^{\mathrm{j}}$ & $2.83^{\mathrm{h}}$ & $3.17^{\mathrm{c}}$ & $3.21^{\mathrm{c}}$ & $3.00^{f}$ \\
\hline Cow's milk & $4.75^{\mathrm{a}}$ & $4.92^{\mathrm{a}}$ & $3.71^{\mathrm{a}}$ & $4.17^{\mathrm{a}}$ & $4.38^{\mathrm{a}}$ \\
\hline
\end{tabular}


Table 3: Acceptability of lemongrass-, honey- and sugar-flavoured soymilk formulations using TGX 1805 - $8 \mathrm{E}$ variety

\begin{tabular}{lccccc}
\hline Composition & Appearance & Colour & Aroma & Taste & $\begin{array}{c}\text { Overall } \\
\text { acceptability }\end{array}$ \\
\hline Soy + sugar & $3.8^{\mathrm{b}}$ & $4.0^{\mathrm{b}}$ & $2.8^{\mathrm{b}}$ & $3.2^{\mathrm{c}}$ & $3.2^{\mathrm{c}}$ \\
Soy + honey+ lemon grass & $3.6^{\mathrm{b}}$ & $3.1^{\mathrm{c}}$ & $3.0^{\mathrm{b}}$ & $3.2^{\mathrm{c}}$ & $3.2^{\mathrm{c}}$ \\
Soy + honey & $3.5^{\mathrm{b}}$ & $3.2^{\mathrm{c}}$ & $3.0^{\mathrm{b}}$ & $3.2^{\mathrm{c}}$ & $3.0^{\mathrm{d}}$ \\
Soy + lemon grass + sugar & $3.5^{\mathrm{b}}$ & $3.0^{\mathrm{c}}$ & $4.2^{\mathrm{a}}$ & $4.6^{\mathrm{a}}$ & $3.8^{\mathrm{b}}$ \\
Cow's milk & $4.7^{\mathrm{a}}$ & $4.9^{\mathrm{a}}$ & $4.2^{\mathrm{a}}$ & $4.3^{\mathrm{a}}$ & $4.6^{\mathrm{a}}$ \\
\hline
\end{tabular}

Values having different superscript letters within a column are statistically different $(\mathrm{p}<0.05)$. 


\section{REFERENCES}

1. MLD. Investment Opportunities in the Livestock Industry, The United Republic of Tanzania, Ministry of Livestock Development. 2006; 30 pp.

2. Bus AEM and A Worsley Consumers' sensory and nutritional perceptions of three types of milk. Public Health Nutrition. 2003; 6(2): 201-208.

3. Shurtleff W and A Aoyagi History of Soymilk and Dairy-like Soymilk Products . A Special Report on The History of Traditional Non-Fermented Soyfoods . A Chapter from the Unpublished Manuscript, History of Soybeans and Soyfoods: 1100 B.C. to the 1980s, 2004.

4. Riaz MN Soy Applications in Foods. CRC Press, Boca Raton, 2006; 275p.

5. Berk Z Chapter 5: Soybean Protein Concentrates (SPC) Technology of Production of Edible Flours and Protein Products from Soybeans, FAO Agricultural Services Bulletin no. 97, FAO, Rome. (http://www.fao.org/docrep/t0532e/t0532e06.htm).

6. Wolf WJ and JC Cowan. Soybeans as a Food Source, CRC. Press, Boca Raton, 1971; pp. 33-77.

7. Welkins WF, Mattick LR and DB Hand Effect of processing method on oxidative off-flavour of soymilk. Food Technology 1967; 21: 1630-1633.

8. Berk Z Chapter 8. Soymilk and related products. In: Technology of Production of Edible Flours and Protein Products From Soybeans; 1992. [http://www.fao.org/docrep/t0532e/to532e09.html] website visited on15 June. 2009.

9. Khaleque A, Bannatyne WR and GM Wallace Studies on the processing and properties of soymilk. 1. Effect of processing conditions on decomposition of soymilks. Journal of Science of Food and Agriculture. 1970; 21: 579-583.

10. Joy PP, Baby P, Skaria SM, Gracy M and J Ancy Lemongrass:the fame of Cochin. Indian J Arecanut, Spices and Medicinal Plants, 2006; 8(2):55-64

11. Dowley C Oh Honey! All About Nature's Nectar. 1999 (http://www.chef2chef.net/articles/in-the-pantry/honey-guide-recipes.html) website visited on 22/10/2009.

12. Cowan JC, Rackis JJ and WJ Wolf Soybean protein flavour components: a review. J Am. Assoc. Oil Chemists' Society. 1973; 50(10): a426-a444. 
13. Rehman S-ur, Nawaz H, Ahmad MM, Hussain S, Murtaza A and SH Shahid Physico-chemical and sensory evaluation of ready to drink soy-cow milk blend. Pakistan Journal of Nutrition. 2007; 6(3): 283-285.

14. Hazen C Optimizing soy/dairy blends. 2007; [http//www.foodproductdesign.com/articles/463/77h911575356044.html] website visited on 7/7/2008.

15. Mai J Lemon Grass Tea The right formula: creating great-tasting soy beverages. 2004; [http:www.functionalinredientsmag.com/fimag/articleDisplay.asp?strArticleId= $362 \& s t r S]$ website visited on 5/7/2008.

16. Messina M Modern application for an ancient bean and the prevention and treatment of chronic diseases. J. Nutr. 1995; 125: 567S-589S.

17. Rabbani SI, Devi K, Khanam S and N Zahra Citral a component of lemongrass oil inhibits the clastogenic effect of nickel chloride in mouse micronucleus test system. Pak. J. Pharm. Sci. 2006; 19(2):108-113.

18. Edmund WL, David R, Erickson WK Food Uses of Whole Oil and Protein Seeds.

[http://books.google.com/books?id=sT0D10cknYYC\&pg=PA50\&lpg=PA50\&d $\mathrm{q}=$ honey $\% 2 \mathrm{~B}$ soymilk\%Bbeany+flavour\%2Bpdf\&source] website visited 9/7/2008. 